\title{
Effect of Exercise Training on Striatal Dopamine D2/D3 Receptors in Methamphetamine Users during Behavioral Treatment
}

\author{
Chelsea L Robertson ${ }^{1,2}$, Kenji Ishibashi, ${ }^{2,3,5}$, Joy Chudzynski ${ }^{3}$, Larissa J Mooney ${ }^{3}$, Richard A Rawson ${ }^{2}$, \\ Brett A Dolezal $^{4}$, Christopher B Cooper ${ }^{4}$, Amira K Brown ${ }^{1,2,6}$, Mark A Mandelkern ${ }^{2}$ and \\ Edythe D London ${ }^{*, 1,2,3}$
}

'Department of Molecular and Medical Pharmacology, David Geffen School of Medicine, University of California, Los Angeles, Los Angeles, CA, USA; ${ }^{2}$ Greater Los Angeles Veterans Affairs Hospital and Health Care System, Los Angeles, CA, USA; ${ }^{3}$ Department of Psychiatry and Biobehavioral Sciences, David Geffen School of Medicine, University of California, Los Angeles, Los Angeles, CA, USA; ${ }^{4}$ Department of Medicine and Physiology, David Geffen School of Medicine, University of California, Los Angeles, Los Angeles, CA, USA

\begin{abstract}
Methamphetamine use disorder is associated with striatal dopaminergic deficits that have been linked to poor treatment outcomes, identifying these deficits as an important therapeutic target. Exercise attenuates methamphetamine-induced neurochemical damage in the rat brain, and a preliminary observation suggests that exercise increases striatal D2/D3 receptor availability (measured as nondisplaceable binding potential $\left(\mathrm{BP}_{\mathrm{ND}}\right)$ ) in patients with Parkinson's disease. The goal of this study was to evaluate whether adding an exercise training program to an inpatient behavioral intervention for methamphetamine use disorder reverses deficits in striatal D2/D3 receptors. Participants were adult men and women who met DSM-IV criteria for methamphetamine dependence and were enrolled in a residential facility, where they maintained abstinence from illicit drugs of abuse and received behavioral therapy for their addiction. They were randomized to a group that received I h supervised exercise training $(n=10)$ or one that received equal-time health education training $(n=9), 3$ days/week for 8 weeks. They came to an academic research center for positron emission tomography $(\mathrm{PET})$ using $\left[{ }^{18} \mathrm{~F}\right]$ fallypride to determine the effects of the 8-week interventions on striatal D2/D3 receptor $B P_{N D}$. At baseline, striatal $D 2 / D 3$ BP ${ }_{N D}$ did not differ between groups. However, after 8 weeks, participants in the exercise group displayed a significant increase in striatal D2/D3 BP $N D$, whereas those in the education group did not. There were no changes in $\mathrm{D} 2 / \mathrm{D} 3 \mathrm{BP} \mathrm{ND}_{\mathrm{N}}$ in extrastriatal regions in either group. These findings suggest that structured exercise training can ameliorate striatal D2/D3 receptor deficits in methamphetamine users, and warrants further evaluation as an adjunctive treatment for stimulant dependence.
\end{abstract}

Neuropsychopharmacology (2016) 4I, 1629-1636; doi:I0.I038/npp.20 I5.33I; published online II November 2015

\section{INTRODUCTION}

Deficits in markers of the striatal dopaminergic system are hallmark features of substance use disorders (Broft and Martinez, 2012), and likely reflect both genetic predisposition and molecular adaptions to repeated drug exposure (Volkow and Baler, 2014). Human neuroimaging studies have shown that chronic methamphetamine users display deficits in striatal dopamine receptors (Lee et al, 2009), dopamine

\footnotetext{
*Correspondence: Dr ED London, Semel Institute, University of California, Los Angeles, 760 Westwood Plaza, C8-83I, Los Angeles, CA 90024, USA, Tel: +I 310825 0606, Fax: + 3108250812 , E-mail: elondon@mednet.ucla.edu

${ }^{5}$ Current address: Tokyo Metropolitan Institute of Gerontology, Tokyo 173-0022, Japan.

${ }^{6}$ Current address: Department of Internal Medicine, Charles R. Drew University of Medicine and Science, Los Angeles, CA, USA.

Received 7 May 2015; revised 25 September 2015; accepted 27 September 2015; accepted article preview online 27 October 2015
}

transporters (McCann et al, 2008), and vesicular monoamine transporters (Johanson et al, 2006).

Other studies have shown a gradual recovery of dopaminergic markers with sustained drug abstinence, with striatal dopamine transporter availability being $20 \%$ greater in subjects who were abstinent 12-17 months compared with those who were abstinent for only 6 months (Volkow et al, 2001). The rate of recovery of dopamine transporter availability varies widely between individuals, and some deficits persist long after cessation of drug use (McCann et al, 2008). In non-human primates, methamphetamine-induced decreases in striatal D2/D3 dopamine receptors persist for over 7 weeks (Groman et al, 2012), whereas similar cocaineinduced deficits persist for up to 1 year (Nader et al, 2006). There are no published reports of recovery of D2/D3 receptors with drug abstinence in human subjects.

Positron emission tomography (PET) imaging studies show that low levels of D2/D3 receptors are associated with drug use and associated behaviors (Broft and Martinez, 
2012). In recently abstinent methamphetamine-dependent individuals (4-7 days), D2/D3 receptor availability is negatively associated with self-reported impulsivity (Lee et al, 2009), discounting of delayed rewards (Ballard et al, 2015), and caloric intake, suggesting that food is used as a substitute reinforcer in a reward deficiency syndrome (Zorick et al, 2012). Moreover, D2/D3 receptor availability and even more so function of the striatal element, as inferred from dopamine release, was positively associated with treatment outcomes for methamphetamine use disorder (Wang et al, 2012). Individual variation in striatal dopamine $\mathrm{D} 2 / \mathrm{D} 3$ binding potential $\left(\mathrm{BP}_{\mathrm{ND}}\right)$ has been linked to cognitive function and associated neural activity in domains such as risky decision making (Kohno et al, 2015) and response inhibition (Ghahremani et al, 2012; Robertson et al, 2015), in which stimulant abusers show deficits. Therefore, increasing signaling through D2/D3 receptors represents a potentially important therapeutic target in the care of individuals with addiction.

In rodents, exercise augmented striatal dopamine concentrations, dopamine receptor binding, and tyrosine hydroxylase mRNA (Greenwood et al, 2011; MacRae et al, 1987). Other studies have shown that wheel running attenuates methamphetamine-induced damage to serotonergic and dopaminergic terminals (Marshall and O'Dell, 2012; O'Dell et al, 2012), as well as D2/D3 dopamine receptor binding in a model of Parkinson's disease (Vuckovic et al, 2010). Moreover, in a pilot study of four patients with earlystage Parkinson's disease, striatal D2/D3 $\mathrm{BP}_{\mathrm{ND}}$ was increased in the two patients who engaged in treadmill exercise but not in the two patients who did not (Fisher et al, 2013). Acute exercise activity, on the other hand, does not affect D2/D3 $\mathrm{BP}_{\mathrm{ND}}$ in healthy subjects, as measured after $30 \mathrm{~min}$ of treadmill running (Wang et al, 2000).

Although it has been suggested that exercise can boost dopamine function during early abstinence from drug use (Lynch et al, 2013), the effects of chronic exercise on the dopamine system have not been studied in humans with addictions. In this study, therefore, PET was used with $\left[{ }^{18} \mathrm{~F}\right]$ fallypride as a radioligand for dopamine D2/D3 receptors (Mukherjee et al, 1999) to examine the effect of an 8-week exercise training program on striatal $\mathrm{D} 2 / \mathrm{D} 3$ receptor $\mathrm{BP}_{\mathrm{ND}}$ in individuals undergoing behavioral treatment for methamphetamine addiction in a residential facility.

\section{MATERIALS AND METHODS}

\section{Study Design}

Subjects recruited into this brain imaging study were concurrently participating in a larger randomized, controlled trial of exercise compared with health education for methamphetamine dependence $(n=135)$ designed to test the impact of an 8-week aerobic exercise regimen $v s$ an 8 -week health education program on methamphetaminedependent individuals who are receiving treatment at a residential treatment facility (Mooney et al, 2014). Those who met entry criteria and expressed interest in continuing were invited to participate in this substudy, involving brain scanning procedures. All participants continued with the regular schedule of treatment activities at the facility, including group and individual therapy and 12-step meetings. Screening to determine eligibility included a medical history, physical examination, clinical laboratory tests, and a 12-lead resting electrocardiogram (ECG). All study procedures were approved by the Institution Review Boards of the University of California Los Angeles (UCLA) and the Greater Los Angeles Veterans Affairs Health Care System. Participants were recruited to this study within $72 \mathrm{~h}$ of admission to the residential facility (CRI-Help, George T. Pfleger Rehabilitation Center, North Hollywood, CA) that they entered for addiction treatment. Each participant was fully informed of the benefits and risks of the study and provided written consent to participate. Eligible participants who passed the health screening procedures began the exercise or education programs 2 weeks after recruitment into the study.

\section{Participants}

Participants were required to be $18-55$ years of age, to reside at the treatment center, and to meet DSM-IV-TR criteria for methamphetamine dependence as determined via the MiniInternational Neuropsychiatric Interview (MINI) (Sheehan et al, 1998). Individuals were excluded if they met criteria for any other axis 1 disorders or dependence on any other drugs of abuse besides nicotine and marijuana. All participants completed a comprehensive medical examination including a urine screen for recent drug use and pregnancy (females only). Exclusionary criteria included any musculoskeletal conditions and unstable cardiovascular, pulmonary, metabolic, or other disorders that would preclude participation in exercise training. Participants with conditions that could either interfere with the acquisition of the neuroimaging data or for whom the neuroimaging procedures would pose a potential risk were excluded (ie, implanted metal objects in the body, claustrophobia, and use of medications known to interact with $\mathrm{D} 2 / \mathrm{D} 3$ receptors).

\section{Baseline Assessment}

All participants completed a baseline maximal incremental exercise test using a symptom-limited incremental treadmill protocol described previously (Dolezal et al, 2014). Briefly, participants were asked to walk on a treadmill with gradually increasing speed and grade as long as they could. Individual performance on the baseline exercise test was used to set parameters for the training intensity of subsequent exercise sessions for each of the exercise group participants. Methamphetamine abstinence was confirmed for each participant by urinalysis upon entry to the study, on a weekly basis during the study, and immediately before all brain scanning procedures.

\section{Exercise Training Group (EX)}

Each participant randomized to the EX group participated in $1 \mathrm{~h}$ individualized exercise sessions 3 days/week for 8 weeks, under the supervision of an experienced exercise trainer, in the gym located within the treatment facility. Participants walked and/or jogged on a treadmill for $30 \mathrm{~min}$ at an intensity determined from the individual's baseline exercise performance. Participants also completed a circuit-type 
resistance training program using weight machines and dumbbell free weights that included all the major muscle groups of the upper and lower body (Dolezal et al, 2014; Mooney et al, 2014).

\section{Education Control Group (ED)}

Each participant randomized to the ED group participated in small-group ( $<5$ participants) health education sessions for $\sim 1 \mathrm{~h}, 3$ times/week for 8 weeks. A trained counselor conducted sessions addressing a variety of health, wellness, and lifestyle topics such as healthy eating, dental care, acupressure, and cancer screening (Mooney et al, 2014). There was no guidance or encouragement to engage in exercise training, although participants in this group did have access to the in-house gym, as did all other residents. The amount of each participant's physical activity outside the study procedures was recorded weekly by self-report as part of the larger study (Mooney et al, 2014). Time spent (min) walking, jogging, lifting weights, playing spots, or other physical activities that were not part of the exercise program of this study were recorded for each day of the week. Weekly combined additional activity totals were summed across all activities. Then, weekly combined activity totals were summed across the length of the study.

\section{PET Scanning}

Dopamine $\mathrm{D} 2 / \mathrm{D} 3$ receptor availability $\left(\mathrm{D} 2 / \mathrm{D} 3 \mathrm{BP}_{\mathrm{ND}}\right)$ was determined before and after the 8-week intervention in both $\mathrm{EX}$ and ED groups. D2/D3 $\mathrm{BP}_{\mathrm{ND}}$ was determined using $\left[{ }^{18} \mathrm{~F}\right]$ fallypride, a radioligand with high affinity for D2/D3 (Mukherjee et al, 1999) PET scanning was performed on a Philips Gemini Tru Flight PET/CT in 3D mode (FWHM $5.0 \mathrm{~mm} \times 4.8 \mathrm{~mm}$, Philips Electronics NV, The Netherlands). The mean administered dose $\left[{ }^{18} \mathrm{~F}\right]$ fallypride was comparable between groups and across conditions (EX (mean MBq (SD): baseline 204.05 (10.61), after intervention 207.49 (8.86). ED: baseline 208.18 (8.08), after intervention 201.81 (8.83)). A CT transmission scan was performed to obtain data for measured attenuation correction. After bolus injection of $\left[{ }^{18} \mathrm{~F}\right]$ fallypride $(\sim 5 \mathrm{mCi}$, specific activity $\geqslant 1 \mathrm{Ci} / \mu \mathrm{mol})$. A total of 160 min of dynamic emission data were acquired in two 80-min blocks that were separated by a short break $(<10 \mathrm{~min})$ to reduce radiation exposure to the bladder wall and relieve participant discomfort. Data were reconstructed using the $3 \mathrm{D}$ row action maximum likelihood algorithm (3D-RAMLA). Scatter and random corrections were applied.

\section{MRI Scanning and VOIs}

MRI scanning was performed on a Siemens Trio (MPRAGE: repetition time $=1.9 \mathrm{~s}$, echo time $=2.26 \mathrm{~ms}$, voxel size $=1 \times 1 \times 1 \mathrm{~mm}^{3}, 176$ slices), and processed using the FMRIB Software Library (FSL; http://fsl.fmrib.ox.ac.uk/fsl/ index.html, Oxford University). Selected volumes of interest (VOIs) included the whole striatum and its functional subdivisions: limbic striatum, associative striatum, and sensory motor striatum. Extrastriatal VOIs for the hippocampus, amygdala, and thalamus were defined using the FSL software package and a whole striatum VOI was created by combining VOIs of the caudate, putamen, and nucleus accumbens. The functional subdivisions of the striatum (Martinez et al, 2011) and midbrain (Zald et al, 2010) were defined using published guidelines. The cerebellum was selected as an appropriate reference region (Hall et al, 1994; Ishibashi et al, 2013). A VOI was drawn manually in MNI-152 space as a bilateral region encompassing both hemispheres while avoiding the vermis. The standard space VOI was then transformed to each subject's native MRI (Ishibashi et al, 2013).

\section{PET Image Processing}

Reconstructed $\left[{ }^{18} \mathrm{~F}\right.$ ]fallypride PET data (2 blocks; $1 \mathrm{~min} \times 80$ frames) were combined into 16 frames, each consisting of the average of $10 \mathrm{~min}$. PET images were motion-corrected then co-registered to the corresponding MRI (Jenkinson et al, 2002). VOI-based time-activity data were extracted for kinetic modeling using PMOD (PMOD 3.1, Zurich). Time-activity curves were fit using the simplified reference tissue model (SRTM) (Lammertsma and Hume, 1996). A volume-weighted average of k2', estimated from high-activity regions (caudate and putamen), was computed. Time-activity curves were then refit using SRTM2 (Wu and Carson, 2002) applying the computed k2' values to all VOIs. Binding potential referred to nondisplaceable uptake $\left(\mathrm{BP}_{\mathrm{ND}}\right)$ was calculated by subtracting 1.0 from the product of $\mathrm{R} 1$ and $\mathrm{k} 2^{\prime} / \mathrm{k} 2 \mathrm{a}$.

\section{Statistical Analysis}

VOIs of the whole striatum and three functional striatal subdivisions were selected a priori because of the high degree of dopaminergic innervation in these regions and existing literature identifying dopaminergic transmission in these regions to be important in the neurobiology of methamphetamine dependence (Broft and Martinez, 2012; Lee et al, 2009; Wang et al, 2012). Exploratory investigations involved D2/D3 $\mathrm{BP}_{\mathrm{ND}}$ measurements from other subcortical regions, specifically the amygdala, midbrain, thalamus, and hippocampus.

Group differences in baseline $\mathrm{BP}_{\mathrm{ND}}$ ( $\mathrm{ED}$ vs $\mathrm{EX}$ ) were evaluated using independent-sample $t$-tests conducted in SPSS (IBM SPSS 22.0, Chicago, IL). Comparisons were made for $\mathrm{BP}_{\mathrm{ND}}$ measurements from the whole striatum VOI. Group differences in $\mathrm{BP}_{\mathrm{ND}}$ for functional striatal subdivisions were compared using post hoc $t$-tests if a significant difference was first identified using the whole-striatum VOI. Group differences in demographic variables (ED vs EX) were compared using independent-sample $t$-tests using SPSS (IBM SPSS 22.0). Using the same statistical tests, baseline $\mathrm{BP}_{\mathrm{ND}}$ was also compared between subjects who did and those who did not complete the study.

Changes in whole striatum $\mathrm{BP}_{\mathrm{ND}}$ between baseline and postintervention $\mathrm{BP}_{\mathrm{ND}}$ as a function of treatment group was tested using a repeated-measures analysis of variance (ANOVA) in SPSS (IBM SPSS 22.0). Taking whole striatum $\mathrm{BP}_{\mathrm{ND}}$ as the dependent variable, the main effects of time (baseline $v s$ after intervention) and group (ED vs EX) were included in the model, and the interaction effect (time $\mathrm{x}$ group) was also included. The post hoc paired $t$-tests were used to test the changes in regional striatal $\mathrm{BP}_{\mathrm{ND}}$ within each treatment group. 


\section{RESULTS}

\section{Participants}

A total of 31 subjects (mean age $29.8 \pm 5.9$ years) were recruited to participate in the brain imaging study; 16 were randomized to the EX group (10 men and 6 women) and 15 to the ED group ( 7 men and 8 women). All underwent PET scanning at baseline, but 12 subjects did not complete the protocol: 6 from the EX group and 6 from the ED group. Eleven of the noncompleters chose to leave the treatment facility, and one participant was withdrawn for medical reasons. Nineteen subjects underwent postintervention PET scanning after completing 8 weeks of exercise training $(n=10)$ or the health education program $(n=9)$.

\section{Demographics}

Participants in the EX and ED groups did not differ on any of the demographic variables examined (Table 1). Most were smokers $(n=29)$ and had completed an average of 11.8 years of education. On average, they reported using methamphetamine for $\sim 8.6$ years, estimating that they had used methamphetamine on 20 of the 30 days preceding admission to the treatment facility. The subjects who did not complete the study did not differ from those who completed the protocol on any of the baseline demographic variables, except for years of methamphetamine use. Those who did not complete the protocol $(n=12)$ had more years of methamphetamine use than those who completed $(n=19)$ the protocol: mean (SD) years 14.7 (6.0) vs 8.6 (4.3); $p=0.006$. No relationships were observed between duration of methamphetamine use and baseline $\mathrm{D} 2 / \mathrm{D} 3 \mathrm{BP}_{\mathrm{ND}}$.

Participants continued treatment as usual at the residential facility, and had similar clinical activities, social responsibilities, and daily meal options. Details of the study design and procedures have been reported previously (Mooney et al, 2014). On average, subjects completed $\sim 22$ of 24 possible sessions, with no group difference in the number of sessions (mean (SD) completed: EX 22.2 (1.8) vs ED 22.4 (1.9) sessions). Body weight increased on average by $6.7 \%$ in the ED group after 8 weeks $(p=0.020)$, whereas mean body weight did not change in the EX group. Additional physical activity for participants in the exercise program $(75 \pm 85 \mathrm{~min}$ per week, mean $\pm S D)$ and the education program $(82 \pm 95$ min) were comparable, and $t$-tests showed no group differences in weekly or cumulative additional physical activity levels.

\section{Effects of EX and ED Interventions on Striatal D2/D3 Dopamine Receptor $\mathbf{B P}_{\mathrm{ND}}$}

Baseline striatal D2/D3 $\mathrm{BP}_{\mathrm{ND}}$ was approximately equal in all striatal regions between completing participants in the two treatment groups (Table 2). There were also no significant differences in baseline $\mathrm{BP}_{\mathrm{ND}}$ in comparisons of participants who did and did not complete the study.

Results from the repeated-measures ANOVA showed a main effect of time on D2/D3 $\mathrm{BP}_{\mathrm{ND}} \quad\left(\mathrm{F}_{1,17}=10.591\right.$, $p=0.005)$, and an effect of treatment group $\times$ time interaction $\left(\mathrm{F}_{1,17}=4.135, p=0.058\right)$, yielding a trend-level effect of exercise on whole striatum $\mathrm{BP}_{\mathrm{ND}}$. The post hoc paired $t$-tests
Table I Characteristics of Participants in the Exercise and Education Groups

\begin{tabular}{lcc}
\hline & Education & Exercise \\
\hline$N$ (men/women) & $9(4 / 5)$ & $10(7 / 3)$ \\
Age (years) & $29.4(7.1)$ & $29.0(3.83)$ \\
Number of smokers & 8 & 8 \\
Years of education & $11.33(3.0)$ & $11.78(1.2)$ \\
Years of methamphetamine use & $8.8(4.7)$ & $8.5(4.1)$ \\
Days of methamphetamine use in past 30 days & $25(8.6)$ & $19.5(10.3)$ \\
Sessions completed (avg) & 22.4 & 22.2 \\
\hline
\end{tabular}

Table 2 Striatal D2/D3 BP ${ }_{\text {ND }}$ at Baseline and After Intervention

\begin{tabular}{lccc}
\hline & Baseline & $\begin{array}{c}\text { After } \\
\text { intervention }\end{array}$ & $\begin{array}{c}\text { Percent } \\
\text { change }^{\mathrm{a}}\end{array}$ \\
\hline $\begin{array}{l}\text { Education group }(\mathrm{n}=9) \\
\text { Whole striatum }\end{array}$ & $26.44(5.31)$ & $27.27(5.26)$ & $3.13 \%$ \\
Limbic & $23.50(4.26)$ & $24.64(4.77)$ & $4.84 \%$ \\
Associative & $25.66(5.24)$ & $26.37(5.76)$ & $2.74 \%$ \\
Sensory motor & $29.57(6.59)$ & $30.31(5.61)$ & $2.51 \%$ \\
& & & \\
Exercise group $(\mathrm{n}=10)$ & & & $13.89 \%$ \\
Whole striatum & $25.80(3.67)$ & $29.38(3.90)^{\mathrm{b}}$ & $7.63 \%$ \\
Limbic & $24.12(2.94)$ & $25.96(2.84)^{\mathrm{b}}$ & $14.92 \%$ \\
Associative & $25.31(3.99)$ & $29.09(4.25)^{\mathrm{b}}$ & $15.88 \%$ \\
Sensory motor & $27.57(3.83)$ & $31.96(4.94)^{\mathrm{b}}$ & \\
\hline
\end{tabular}

Values represent mean (SD)

Baseline $\mathrm{BP}_{\mathrm{ND}}$ comparisons between subjects who did $(n=19)$ and those who did not $(n=\mid \mathrm{I})$ complete the study revealed no significant differences in whole striatum (26.10 (4.3) vs (26.93 (3.4)), completers vs noncompleters, limbic striatum (23.82 (3.4) vs (23.06 (3.9)), associative striatum (25.50 (4.4)) vs (26.53 (4.I)), and sensory motor striatum (28.49 (5.I)) vs (29.6I (4.5)).

a Percent change in mean.

${ }^{b} P<0.0$ I paired t-tests to compare baseline $\mathrm{BP}_{\mathrm{ND}}$ with postintervention $\mathrm{BP}_{\mathrm{ND}}$.

were conducted for exploratory purposes to investigate the regional effects of exercise in this small sample. Paired $t$-tests showed a significant increase in the whole striatum $\mathrm{D} 2 / \mathrm{D} 3 \mathrm{BP}_{\mathrm{ND}}$ in the EX group $(t=3.917, p=0.004)$ but not in the $\mathrm{ED}$ group $(t=0.848, p=0.421)$. All functional striatal subdivisions showed similar increases in the EX group by paired $t$-tests: limbic: $t=3.04, p=0.014$; associative: $t=3.51$, $p=0.007$; and sensory motor: $t=3.691, p=0.005$.

Participants in the EX group displayed an average $13.89 \%$ increase in $\mathrm{D} 2 / \mathrm{D} 3 \mathrm{BP}_{\mathrm{ND}}$ in the whole striatum whereas those in the ED group displayed an average increase of $3.13 \%$. The EX group participants showed, on average, increases of 14.92 and $15.88 \%$ in the associative and sensory motor regions, respectively, and $7.63 \%$ in the limbic striatum (Figure 1). The ED group participants showed average increases of 4.84, 2.74 and $2.51 \%$ in the limbic, associative, and sensory motor regions of striatum, respectively (Figure 1). 


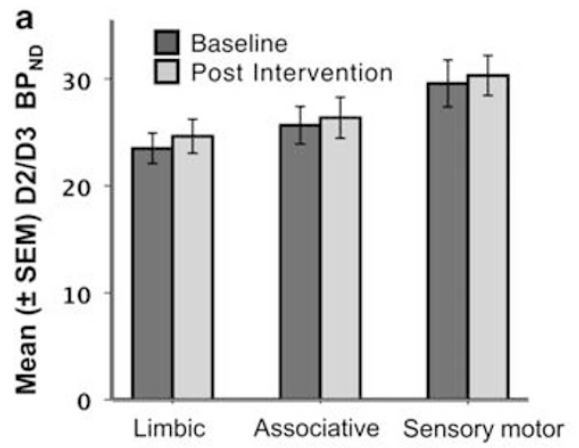

Education

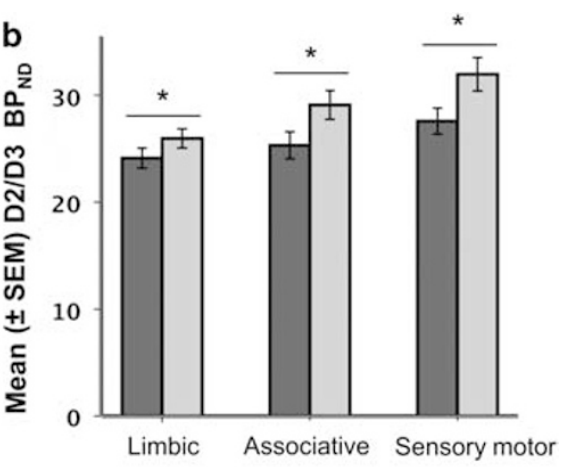

Exercise

Figure I Bar graph depicting change in mean striatal D2/D3 BP $P_{N D}$ after completion of an 8-week education (a) and exercise (b) program. *P $<0.0$ I using paired $t$-tests to compare baseline with postintervention $\mathrm{BP}_{\mathrm{ND}}$ values. Errors bars represent $\mathrm{I} \pm \mathrm{SEM}$.

\section{Effects in Extrastriatal Regions}

Exploratory investigations of $\mathrm{D} 2 / \mathrm{D} 3 \mathrm{BP}_{\mathrm{ND}}$ measurements in the amygdala, hippocampus, thalamus, and midbrain showed no group differences in $\mathrm{BP}_{\mathrm{ND}}$ at baseline or after intervention (see Table 3). There were no significant changes from baseline at the post intervention PET scan, but thalamus $\mathrm{BP}_{\mathrm{ND}}$ showed a trend-level increase in the $\operatorname{ED}$ group $(t=2.18$, $p=0.060$ ).

\section{DISCUSSION}

The present findings add to a preliminary report of an effect of exercise on striatal dopamine receptors in humans (Fisher et al, 2013), and on methamphetamine neurotoxicity in rodents (Marshall and O'Dell, 2012; O'Dell et al, 2012) by providing evidence that exercise increases striatal D2/D3 $\mathrm{BP}_{\mathrm{ND}}$ in methamphetamine users. Although 8 weeks of drug abstinence in addition to behavioral treatment did not significantly change striatal D2/D3 receptor availability, addition of an exercise training program produced significant increases. These findings demonstrate that methamphetamine-associated deficits in the D2/D3 receptor system are reversible in human subjects, and that recovery of the dopamine system after chronic drug use can be facilitated with exercise training.

A deficit in striatal D2/D3 dopamine receptor binding is a common feature across substance use disorders (Bonci et al, 2013; Broft and Martinez, 2012). In stimulant dependence, this deficit is linked to treatment success rates (Martinez et al, 2011; Wang et al, 2012) and measures of impulsivity (Lee et al, 2009) and decision making (Ballard et al, 2015). Although these observations suggest that augmenting signaling at $\mathrm{D} 2 / \mathrm{D} 3$ receptors may be an effective therapeutic target in substance use disorders, dopamine agonist therapy has shown limited success in improving treatment outcomes for stimulant dependence (Ling et al, 2006). Given the intricate biphasic signaling motif of the dopamine system via D1/D5 and D2/D3 receptor-mediated pathways (Gerfen and Surmeier, 2011), it is possible that indirect dopamine agonists would have a larger effect on D1/D5 over D2/D3 receptor signaling, thus disrupting the balance between striatal dopaminergic pathways. This effect would likely be further compounded in patients with D2/D3 receptor deficits, such as those seen in drug addictions (Broft and
Table 3 Extrastriatal D2/D3 BP ND at Baseline and After Intervention

\begin{tabular}{lll}
\hline & Baseline & After intervention \\
\hline Education group $(\mathrm{n}=9)$ & & \\
Amygdala & $2.67(0.4 \mathrm{I})$ & $2.7 \mathrm{I}(0.38)$ \\
Hippocampus & $1.05(0.36)$ & $1.09(0.24)$ \\
Thalamus & $2.44(0.49)$ & $2.53(0.44)$ \\
Midbrain & $2.43(0.2 \mathrm{I})$ & $2.30(0.09)$ \\
& & \\
Exercise group $(\mathrm{n}=10)$ & & \\
Amygdala & $2.68(0.35)$ & $2.76(0.31)$ \\
Hippocampus & $1.01(0.23)$ & $1.06(0.21)$ \\
Thalamus & $2.34(0.32)$ & $2.44(0.26)$ \\
Midbrain & $2.44(0.28)$ & $2.45(0.18)$ \\
\hline
\end{tabular}

Martinez, 2012). Moreover, pharmacological treatment with nonselective D2/D3 receptor agonists may have untoward effects by augmenting D3 vs D2 receptor signaling. Notably, stimulant users show greater D3 receptor availability in the limbic striatum compared with healthy control subjects (Boileau et al, 2012). Therefore, nonpharmacologic approaches, such as structured exercise training, that augment dopaminergic signaling in physiologically relevant ways may be useful in treating those with substance use disorders.

Several lines of evidence suggest that high levels of striatal D2/D3 dopamine receptors may be protective for an individual against drug addiction. For example, unaffected family members of those with alcohol use disorders display higher D2/D3 receptor availability than affected family members, and higher D2/D3 receptor availability than nonrelated healthy control subjects, supporting the hypothesis that high levels of D2/D3 receptors may protect against alcoholism (Volkow et al, 2006). PET studies of stimulant use in humans show an inverse relationship between D2/D3 receptor availability and positive subjective response to intravenous methylphenidate administration. Individuals with high D2/D3 receptor availability report more unpleasant subjective effects, suggesting that they may be less vulnerable to stimulant abuse (Volkow et al, 1999). Moreover, striatal D2/D3 receptor availability in drug-naive rhesus 
monkeys is negatively correlated with the amount of drug taken by animals when trained to self-administer cocaine (Nader et al, 2006). Finally, rats exhibit decreased alcohol self-administration after being subjected to an adenoviralmediated increase in striatal D2 receptor expression (Thanos et al, 2001).

In animal models, exercise produces the most pronounced effects on striatal dopaminergic markers in the dopaminedepleted compared with nondepleted striatum. In the MPTP animal model of Parkinson's disease, 6 weeks of treadmill exercise produces larger increases in $\mathrm{D} 2 / \mathrm{D} 3 \mathrm{BP}_{\mathrm{ND}}$ in animals treated with MPTP than those treated with saline (Vuckovic et al, 2010). In rodent models of methamphetamine-induced dopamine depletion, exercise increases striatal levels of dopamine transporter and tyrosine hydroxylase in the methamphetamine-treated animals, with only minimal effects in saline-treated animals (O'Dell et al, 2012). Analogously, exercise increased $\mathrm{D} 2 / \mathrm{D} 3 \mathrm{BP}_{\mathrm{ND}}$ by $\sim 80 \%$ in two patients with early-stage Parkinson's disease, whereas it only increased D2/ $\mathrm{D} 3 \mathrm{BP}_{\mathrm{ND}}$ by $\sim 9 \%$ in a healthy control subject (Fisher et al, 2013). Although healthy control subjects were not examined in this investigation, exercise-induced increases in D2/D3 receptors observed here were confined only to regions that show dopaminergic deficits in stimulant users (Lee et al, 2009; Volkow et al, 2001).

Hypofunction of the striatal dopaminergic system occurs during abstinence from stimulant use and is associated with anhedonia, negative affect, and drug craving (Volkow and Baler, 2014). Methamphetamine-dependent individuals report symptoms of depression and drug craving (Zorick et al, 2010). Results from the larger clinical trial (Mooney et al, 2014) in which all subjects included in this study were enrolled showed significant effects of the exercise regimen to improve symptoms of depression and anxiety (Rawson et al, 2015). The neuroimaging findings presented here suggest that exercise-induced increases in $\mathrm{D} 2 / \mathrm{D} 3 \mathrm{BP}_{\mathrm{ND}}$ may contribute to these behavioral effects, but direct examination of this relationship in the small neuroimaging subsample failed to detect any significant associations between improvements in ratings of affect and changes in D2/D3 dopamine receptor $\mathrm{BP}_{\mathrm{ND}}$. Additional research is needed to identify the neurobiological mechanisms that underlie exercise-induced amelioration of negative affect in stimulant users.

Although the molecular effects of aerobic exercise are incompletely understood, exercise increases levels of neurotrophic factors and enhances neurogenesis, immune function, and neuroplasticity (Cotman and Berchtold, 2002). The mechanisms by which exercise induces upregulation of D2/ D3 receptors have been investigated in animal models of striatal dopaminergic injury, modeling Parkinson's disease physiology. In rodents, wheel running after stimulant exposure produces significant changes in gene transcription factors capable of modulating dopaminergic neurotransmission in the mesolimbic pathways (Greenwood et al, 2011; Zlebnik et al, 2014), and wheel running attenuates MPTPinduced damage to dopaminergic cells in wild-type mice, but not in BDNF (+/ - ) knockdown mice (Gerecke et al, 2012). Similarly, BDNF receptor antagonists blocked the effects of treadmill running against damage to dopaminergic neurons, as indicated by preserved levels of tyrosine hydroxlase activity, in a rat model of Parkinson's disease using striatal injection of 6-hydroxydopamine (Real et al, 2013).
Some limitations of this study warrant mention. The first relates to the relatively small size of the sample and the fact that findings may not generalize to all methamphetamine users or to those who are not exposed to exercise in a treatment setting. The size of this sample also limits the degree to which potential sex-dependent effects of exercise can be examined in this study (Lynch et al, 2013). Generalizability of the findings may be compromised by exclusion of individuals with Axis I disorders, other than methamphetamine dependence, because such psychiatric comorbidity is common among methamphetamine users.

In addition, although cigarette use was controlled during scan days, subjects continued to smoke throughout the study. As part of the larger study that included the work presented here, the number of cigarettes smoked per week as indicated by self-report was recorded (Mooney et al, 2014). Although participants in the ED group smoked slightly more cigarettes than those in the EX group at baseline (average cigarettes per week: $40 \pm 13.6$ in the EX group and $55.3 \pm 9.8$ in the ED group) and after completing the program (average cigarettes per week: $46 \pm 13.9$ in the EX group and $69 \pm 13.9$ in the ED group), $t$-tests showed there were no significant group differences at either time point. No effect of a group by time point interaction on the weekly number of cigarettes smoked was detected.

Another limitation of the study is the imperfect selectivity of $\left[{ }^{18} \mathrm{~F}\right]$ fallypride that has nearly equal affinity for D2 and D3 dopamine receptors in vivo (Mukherjee et al, 1999) and cannot therefore distinguish between them. Thus, $\mathrm{BP}_{\mathrm{ND}}$ measurements primarily reflect a combination of signals from D2 and $\mathrm{D} 3$ receptors. $\left[{ }^{18} \mathrm{~F}\right]$ fallypride also binds to both isoforms of the D2 receptor (D2S and D2L), and therefore does not distinguish between pre- and postsynaptic D2 receptors. Similarly, D2/D3 receptor $\mathrm{BP}_{\mathrm{ND}}$ estimates made using $\left[{ }^{18} \mathrm{~F}\right]$ fallypride are sensitive to competition from intrasynaptic dopamine. Of relevance is the low (5-10\%) test-retest variation in $\mathrm{BP}_{\mathrm{ND}}$ measurements made using $\left[{ }^{18} \mathrm{~F}\right]$ fallypride (Dunn et al, 2013; Fujita et al, 2006), and the observation that administration of $\alpha$-methyl-p-tyrosine to reduce brain concentrations of dopamine has no effect on $\left[{ }^{18} \mathrm{~F}\right]$ fallypride binding in healthy subjects (Cropley et al, 2008).

Although the focus of this investigation is the dopaminergic system, exercise has many effects on other neurotransmitter systems, including the serotonin, glutamate, and opioid systems (Greenwood et al, 2011). In addition, the effects of exercise on physiological systems outside of the brain are numerous, including cardiovascular, immune, and endocrine systems (Hillman et al, 2008). Earlier findings from a different subsample of the same clinical trial of exercise and methamphetamine dependence (Mooney et al, 2014) showed that exercise training improved heart rate variability, an index of autonomic nervous system balance, that is abnormal in methamphetamine users (Dolezal et al, 2014). Investigations to assess the degree to which exerciseinduced changes in physiological measures are related to changes in neurobiological indices would prove clinically useful as a method to assess disease severity (Devos et al, 2003), or to monitor response to treatment and progression of recovery.

Our findings contribute to a growing literature identifying the therapeutic benefits of exercise in health and disease (Hillman et al, 2008), and also in the treatment of substance 
abuse (Lynch et al, 2013). Exercise is gaining attention as a complement to traditional pharmacological and psychotherapeutic treatments. Therefore, investigating the effects of exercise in patients with neuropsychiatric disorders featuring dopaminergic dysfunction, such as Parkinson's disease (Dagher and Robbins, 2009), drug addictions (Bonci et al, 2013), and attention deficit disorder (Volkow et al, 2011), is of increasing clinical relevance. Understanding the molecular mechanisms by which exercise affects dopaminergic signaling in patients with stimulant use disorders may produce new clinical approaches to enhance treatment outcomes for addictions and other related neuropsychiatric disorders.

\section{FUNDING AND DISCLOSURE}

The authors declare no conflict of interest. Dr Cooper reports personal fees from Astra Zeneca, BoehringerIngelheim, eResearch Technologies, Equinox Health Clubs, Forest, GlaxoSmithKline, Pulmonx, Spriration, and Sunovion; and research funding from Amgen, Equinox Health Clubs and Spiration, all unrelated to this work.

\section{REFERENCES}

Ballard ME, Mandelkern MA, Monterosso JR, Hsu E, Robertson CL, Ishibashi $\mathrm{K}$ et al (2015). Low dopamine D2/D3 receptor availability is associated with steep discounting of delayed rewards in methamphetamine dependence. Int J Neuropsychopharmacol 18: pyul19.

Boileau I, Payer D, Houle S, Behzadi A, Rusjan PM, Tong J et al (2012). Higher binding of the dopamine D3 receptor-preferring ligand [11C]-(+)-propyl-hexahydro-naphtho-oxazin in methamphetamine polydrug users: a positron emission tomography study. J Neurosci 32: 1353-1359.

Bonci A, Volkow, Robertson, Berman London (2013). Molecular imaging in addictive disorders. In: Charney N, Sklar Buxbaum (eds). Neurobiology of Mental Illness, 4th edn. Oxford University Press: Oxford, UK.

Broft A, Martinez D (2012). Neurochemical imaging of addictive disorders. In: Gründer G (ed). Molecular Imaging in the Clinical Neurosciences. Humana Press, New York, Vol 71, pp 249-271.

Cotman CW, Berchtold NC (2002). Exercise: a behavioral intervention to enhance brain health and plasticity. Trends Neurosci 25: 295-301.

Cropley VL, Innis RB, Nathan PJ, Brown AK, Sangare JL, Lerner A et al (2008). Small effect of dopamine release and no effect of dopamine depletion on $[18 \mathrm{~F}]$ fallypride binding in healthy humans. Synapse 62: 399-408.

Dagher A, Robbins TW (2009). Personality, addiction, dopamine: insights from Parkinson's disease. Neuron 61: 502-510.

Devos D, Kroumova M, Bordet R, Vodougnon H, Guieu JD, Libersa C et al (2003). Heart rate variability and Parkinson's disease severity. J Neural Transm 110: 997-1011.

Dolezal BA, Chudzynski J, Dickerson D, Mooney L, Rawson RA, Garfinkel A et al (2014). Exercise training improves heart rate variability after methamphetamine dependency. Med Sci Sports Exerc 46: 1057-1066.

Dunn JT, Clark-Papasavas C, Marsden P, Baker S, Cleij M, Kapur S et al (2013). Establishing test-retest reliability of an adapted [(18)F] fallypride imaging protocol in older people. J Cereb Blood Flow Metab 33: 1098-1103.

Fisher BE, Li Q, Nacca A, Salem GJ, Song J, Yip J et al (2013). Treadmill exercise elevates striatal dopamine D2 receptor binding potential in patients with early Parkinson's disease. Neuroreport 24: 509-514.

Fujita M, Cropley V, Nathan P, Brown A, Sangare J, Ryu Y et al (2006). Test retest reproducibility and influence of dopamine levels on [18F]fallypride PET quantification. J Nucl Med Meeting Abstracts 47(Suppl_1): 282P.

Gerecke KM, Jiao Y, Pagala V, Smeyne RJ (2012). Exercise does not protect against MPTP-induced neurotoxicity in BDNF haploinsufficient mice. PLoS One 7: e43250.

Gerfen CR, Surmeier DJ (2011). Modulation of striatal projection systems by dopamine. Annu Rev Neurosci 34: 441-466.

Ghahremani DG, Lee B, Robertson CL, Tabibnia G, Morgan AT, De Shetler $N$ et al (2012). Striatal dopamine $\mathrm{D}(2) / \mathrm{D}(3)$ receptors mediate response inhibition and related activity in frontostriatal neural circuitry in humans. J Neurosci 32: 7316-7324.

Greenwood BN, Foley TE, Le TV, Strong PV, Loughridge AB, Day HE et al (2011). Long-term voluntary wheel running is rewarding and produces plasticity in the mesolimbic reward pathway. Behav Brain Res 217: 354-362.

Groman SM, Lee B, Seu E, James AS, Feiler K, Mandelkern MA et al (2012). Dysregulation of d2-mediated dopamine transmission in monkeys after chronic escalating methamphetamine exposure. J Neurosci 32: 5843-5852.

Hall H, Sedvall G, Magnusson O, Kopp J, Halldin C, Farde L (1994). Distribution of D1- and D2-dopamine receptors, and dopamine and its metabolites in the human brain. Neuropsychopharmacology 11: 245-256.

Hillman CH, Erickson KI, Kramer AF (2008). Be smart, exercise your heart: exercise effects on brain and cognition. Nat Rev Neurosci 9: 58-65.

Ishibashi K, Robertson CL, Mandelkern MA, Morgan AT, London ED (2013). The simplified reference tissue model with $18 \mathrm{~F}$-fallypride positron emission tomography: choice of reference region. Mol Imaging 12: 1536-0121.

Jenkinson M, Bannister P, Brady M, Smith S (2002). Improved optimization for the robust and accurate linear registration and motion correction of brain images. Neuroimage 17: 825-841.

Johanson CE, Frey KA, Lundahl LH, Keenan P, Lockhart N, Roll J et al (2006). Cognitive function and nigrostriatal markers in abstinent methamphetamine abusers. Psychopharmacology (Berl) 185: 327-338.

Kohno M, Ghahremani DG, Morales AM, Robertson CL, Ishibashi K, Morgan AT et al (2015). Risk-taking behavior: dopamine D2/D3 receptors, feedback, and frontolimbic activity. Cereb Cortex 25: 236-245.

Lammertsma AA, Hume SP (1996). Simplified reference tissue model for PET receptor studies. Neuroimage 4(3 Pt 1): 153-158.

Lee B, London ED, Poldrack RA, Farahi J, Nacca A, Monterosso JR et al (2009). Striatal dopamine $\mathrm{d} 2 / \mathrm{d} 3$ receptor availability is reduced in methamphetamine dependence and is linked to impulsivity. J Neurosci 29: 14734-14740.

Ling W, Rawson R, Shoptaw S, Ling W (2006). Management of methamphetamine abuse and dependence. Curr Psychiatry Rep 8: 345-354.

Lynch WJ, Peterson AB, Sanchez V, Abel J, Smith MA (2013). Exercise as a novel treatment for drug addiction: a neurobiological and stagedependent hypothesis. Neurosci Biobehav Rev 37: 1622-1644.

MacRae PG, Spirduso WW, Cartee GD, Farrar RP, Wilcox RE (1987). Endurance training effects on striatal D2 dopamine receptor binding and striatal dopamine metabolite levels. Neurosci Lett 79: 138-144.

Marshall JF, O’Dell SJ (2012). Methamphetamine influences on brain and behavior: unsafe at any speed? Trends Neurosci 35: 536-545.

Martinez D, Carpenter KM, Liu F, Slifstein M, Broft A, Friedman AC et al (2011). Imaging dopamine transmission in cocaine dependence: link between neurochemistry and response to treatment. Am J Psychiatry 168: 634-641. 
McCann UD, Kuwabara H, Kumar A, Palermo M, Abbey R, Brasic J et al (2008). Persistent cognitive and dopamine transporter deficits in abstinent methamphetamine users. Synapse 62: 91-100.

Mooney LJ, Cooper C, London ED, Chudzynski J, Dolezal B, Dickerson D et al (2014). Exercise for methamphetamine dependence: rationale, design, and methodology. Contemp Clin Trials 37: 139-147.

Mukherjee J, Yang ZY, Brown T, Lew R, Wernick M, Ouyang X et al (1999). Preliminary assessment of extrastriatal dopamine D-2 receptor binding in the rodent and nonhuman primate brains using the high affinity radioligand, 18F-fallypride. Nucl Med Biol 26: 519-527.

Nader MA, Morgan D, Gage HD, Nader SH, Calhoun TL, Buchheimer $\mathrm{N}$ et al (2006). PET imaging of dopamine D2 receptors during chronic cocaine self-administration in monkeys. Nat Neurosci 9: 1050-1056.

O’Dell SJ, Galvez BA, Ball AJ, Marshall JF (2012). Running wheel exercise ameliorates methamphetamine-induced damage to dopamine and serotonin terminals. Synapse 66: 71-80.

Rawson RA, Chudzynski J, Gonzales R, Mooney L, Dickerson D, Ang A et al (2015). The impact of exercise on depression and anxiety symptoms among abstinent methamphetaminedependent individuals in a residential treatment setting. J Subst Abuse Treat 57: 36-40.

Real CC, Ferreira AF, Chaves-Kirsten GP, Torrao AS, Pires RS, Britto LR (2013). BDNF receptor blockade hinders the beneficial effects of exercise in a rat model of Parkinson's disease. Neuroscience 237: 118-129.

Robertson CL, Ishibashi K, Mandelkern MA, Brown AK, Ghahremani DG, Sabb F et al (2015). Striatal D1- and D2-type dopamine receptors are linked to motor response inhibition in human subjects. J Neurosci 35: 5990-5997.

Sheehan DV, Lecrubier Y, Sheehan KH, Amorim P, Jana J, Weiller E et al (1998). The Mini-International Neuropsychiatric Interview (M.I.N.I.): The development and validation of a structured diagnostic psychiatric interview for DSM-IV and ICD-10. J Clin Psychiatry 59(Suppl 20): 22-33 quiz 34-57.

Thanos PK, Volkow ND, Freimuth P, Umegaki H, Ikari H, Roth G et al (2001). Overexpression of dopamine D2 receptors reduces alcohol self-administration. J Neurochem 78: 1094-1103.

Volkow ND, Baler RD (2014). Addiction science: uncovering neurobiological complexity. Neuropharmacology 76(Pt B): 235-249.

Volkow ND, Chang L, Wang GJ, Fowler JS, Franceschi D, Sedler M et al (2001). Loss of dopamine transporters in methamphetamine abusers recovers with protracted abstinence. J Neurosci 21: 9414-9418.

Volkow ND, Wang GJ, Begleiter H, Porjesz B, Fowler JS, Telang F et al (2006). High levels of dopamine D2 receptors in unaffected members of alcoholic families: possible protective factors. Arch Gen Psychiatry 63: 999-1008.

Volkow ND, Wang GJ, Fowler JS, Logan J, Gatley SJ, Wong C et al (1999). Reinforcing effects of psychostimulants in humans are associated with increases in brain dopamine and occupancy of D (2) receptors. J Pharmacol Exp Ther 291: 409-415.

Volkow ND, Wang GJ, Newcorn JH, Kollins SH, Wigal TL, Telang $\mathrm{F}$ et al (2011). Motivation deficit in ADHD is associated with dysfunction of the dopamine reward pathway. Mol Psychiatry 16: 1147-1154.

Vuckovic MG, Li Q, Fisher B, Nacca A, Leahy RM, Walsh JP et al (2010). Exercise elevates dopamine D2 receptor in a mouse model of Parkinson's disease: in vivo imaging with [(1)(8)F] fallypride. Mov Disord 25: 2777-2784.

Wang GJ, Smith L, Volkow ND, Telang F, Logan J, Tomasi D et al (2012). Decreased dopamine activity predicts relapse in methamphetamine abusers. Mol Psychiatry 17: 918-925.

Wang GJ, Volkow ND, Fowler JS, Franceschi D, Logan J, Pappas NR et al (2000). PET studies of the effects of aerobic exercise on human striatal dopamine release. J Nucl Med 41: $1352-1356$.

Wu Y, Carson RE (2002). Noise reduction in the simplified reference tissue model for neuroreceptor functional imaging. J Cereb Blood Flow Metab 22: 1440-1452.

Zald DH, Woodward ND, Cowan RL, Riccardi P, Ansari MS, Baldwin RM et al (2010). The interrelationship of dopamine D2-like receptor availability in striatal and extrastriatal brain regions in healthy humans: a principal component analysis of [18F] fallypride binding. Neuroimage 51: 53-62.

Zlebnik NE, Hedges VL, Carroll ME, Meisel RL (2014). Chronic wheel running affects cocaine-induced c-Fos expression in brain reward areas in rats. Behav Brain Res 261: 71-78.

Zorick T, Lee B, Mandelkern MA, Fong T, Robertson C, Ghahremani DG et al (2012). Low striatal dopamine receptor availability linked to caloric intake during abstinence from chronic methamphetamine abuse. Mol Psychiatry 17: 569-571.

Zorick T, Nestor L, Miotto K, Sugar C, Hellemann G, Scanlon G et al (2010). Withdrawal symptoms in abstinent methamphetaminedependent subjects. Addiction 105: 1809-1818. 